\title{
An Analysis of the Ecological Features of Stilted Building in Yanzibian, Southern Shaanxi, China
}

\author{
Xiaomeng $\mathrm{Qi}^{1} \&$ Yanjun $\mathrm{Li}^{1}$ \\ ${ }^{1}$ College of Art and Design, Xi'an University of Technology, Xi'an, China \\ Correspondence: Xiaomeng Qi, College of Art and Design, Xi'an University of Technology, Xi'an 710054, \\ China. E-mail: 754774060@qq.com
}

Received: November 26, 2013 Accepted: December 26, 2013 Online Published: December 30, 2013

doi:10.5539/ach.v6n1p72

URL: http://dx.doi.org/10.5539/ach.v6n1p72

Source of the subject: Humanities and Social Sciences Research Plan Fund of the Ministry of Education

"Traditional Shaanxi Residential Building Art and Cultural Heritage of Residential Customs (Emergency) Research" (12YJAZH064).

\begin{abstract}
Silted building is one of the most characteristic traditional residential building types. In the historical process of social transition, silted building has powerful ecological adaptability. Nowadays, there are only a limited number of silted buildings in the Southern Shaanxi region. Thus, this paper is aimed to acquire the first hand data by a field survey on the silted buildings in Yanzibian in Hanzhong, Southern Shaanxi region. Through an analysis of its building idea and technique, the paper interprets the ecological features of silted building in terms of aesthetic consciousness, selection of site, pattern, material usage and building technique, etc. The research result is aimed to provide a lot of referential influences and value for residential buildings and construction of new rural areas in the future and to provide enlightenment for design of ecological buildings.
\end{abstract}

Keywords: traditional residential building, silted building, ecological feature

\section{Introduction}

Building is the carrier of culture. Through the ontology of building, we are able to know about its cultural transition, belief and worship as well as the local customs. Also, we can have an idea about how the building adapts to the survival environment. All this can be embodied thoroughly in building. This paper interprets and perceives the ecological features of silted building by studying the mountainous form of silted buildings in Yanzibian in Hanzhong, Southern Shaanxi.

\section{Overview}

Southern Shaanxi refers to the area in the southern part of Shaanxi Province and contains the three areas of Hanzhong, Ankang and Shangluo ranging from the west to the east. Yanzibian is located in the western part of Ningqiang County in Hanzhong City, Shaanxi Province. It is neighboring to Sichuan Province and Gansu Province and is connected to Yangpingguan Town and Anle River. As it is located in the intersection between the two rivers of Jialing River and Anle River, Yanzibian is one of the four ancient ferries in Ningqiang County. Yanzibian is named as its form is similar to a swallow that soars with lifted wings. In Yanzibian, beautiful mountains and clear waters are everywhere and the scenery is as beautiful as a picture (See Figure 1). Until now, at the mouth of the shore of Yanzibian stand tall and upright only a few silted buildings. 


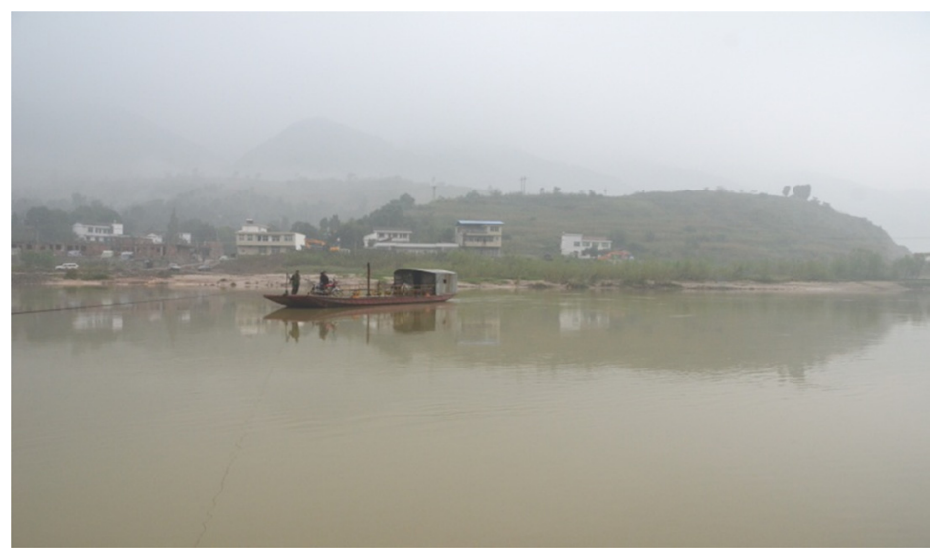

Figure 1. Vessels in the ferry of Yanzibian

Silted building is one type of stilt style architecture, so it is also called stilt style building. It has long been termed as "a live fossil" in the culture of Ba-Shu. It stands nearby the water and is constructed next to the mountains. It collects the anima of green hills and clear water and is integrated into one whole with the great nature. A silted building can be regarded as a pretty girl of humble birth among the cluster of buildings as it is small and exquisite, delicate and pretty. It does not only fit with the simple aesthetic consciousness of local people, but also manifests perfect conformity with the great nature.

\section{Traditional Building Theory and Pattern}

\subsection{Selection of Site - The Geomantic Omen Thought of Syncretism between Heaven and Man}

To comply with the climatic condition, such as, "get up at sunrise and rest at sundown", which is an agricultural farming culture is the work and rest mode of "syncretism between heaven and man". In the ancient times, the thought that the stars change in positions and that the four seasons run determined people's life and production. According to the ancient people, man should not offend the authority of the nature and insistence to "syncretism between heaven and man" is the way of survival (Zhou Mi, 2012, p. 2). In the philosophical concept of the ancient people, both the "moderate" and "producing and reproducing (creativity)" of the Confucian School and the thought of "Tao way follows the nature" of the Taoist School described the relationship between man and the nature as a kind of balance and harmony in a movement. The so-called "syncretism between heaven and man" is that the daily activity of man should realize a kind of harmonious, rational and balanced process of energy exchange with operation of the natural ecology.

Selection of the site for settlement, architectural composition and construction style should take into comprehensive consideration of all kinds of natural and production and living factors. After observation and practice for a long period of time, the ancient people have summarized a thought and method that has the guiding effect on architecture. This is the so-called geomantic omen theory. Geomantic omen was of great significance in the ancient construction practice, which is exactly the reflection of the concept of "syncretism between heaven and man". Although the geomantic omen theory is not science in its strict sense, it does not completely fall into the sphere of superstition. In essence, geomantic omen is a kind of cognitive mode about selection of building site, pattern and construction of the building that the ancient people developed to pursue good fortune and avoid disaster and search for an ideal residential environment. Just as the common people say, a good geomantic omen should be back to the mountain and next to the river and face the south with a wide vision. The best site selected is supposed to "water on the left as an azure dragon, road on the right as a white tiger, pool in the front as a rosefinch and hill at the back as a black tortoise" (Jing Qimin \& Zhang Li'an, 2010, p6). (See Figure 2) Thus, it can be found that, the geomantic omen theory actually implies profound ecological foundation. 


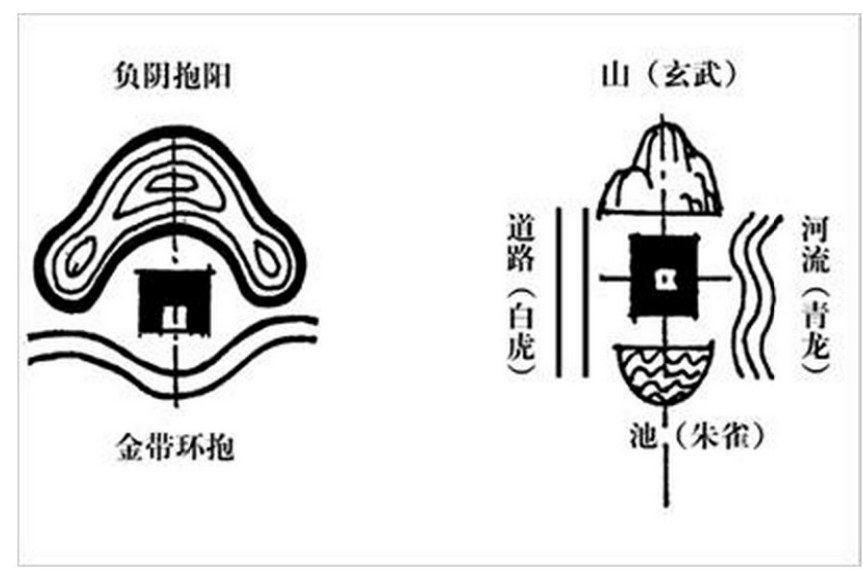

Figure 2. Diagram form of traditional site selection

Yanzibian is located between the valley and the river and its terrain and elevation are relatively low, with abundant rainwater and humid and muggy climate. Whenever the flood season approaches, the water level runs high rapidly. In the face of such environmental change, the ancients had to make prudent choice in the issue of residence. They had to adapt to the natural landform and geomorphology in selection of the site of the settlement and deal with the relations between river system, sunshine, disaster prevention and plough, etc. The site selected should be back to the mountain and next to the river and close to farmland, mountain forest and water source for the convenience of production and cultivation of remaining land and for building a convenient residential environment. Mountains in Yanzibian overlap and are continuous and the water system zigzags. This forms an ambient space and its boundary and entrance is narrow, which is able to hide wind and collect air for convenience of protection (See Figure 3). In order to prevent the buildings from being damaged by flood when the flood season comes, people choose to build the building construction pattern of constructing silted buildings to adapt to the nature.

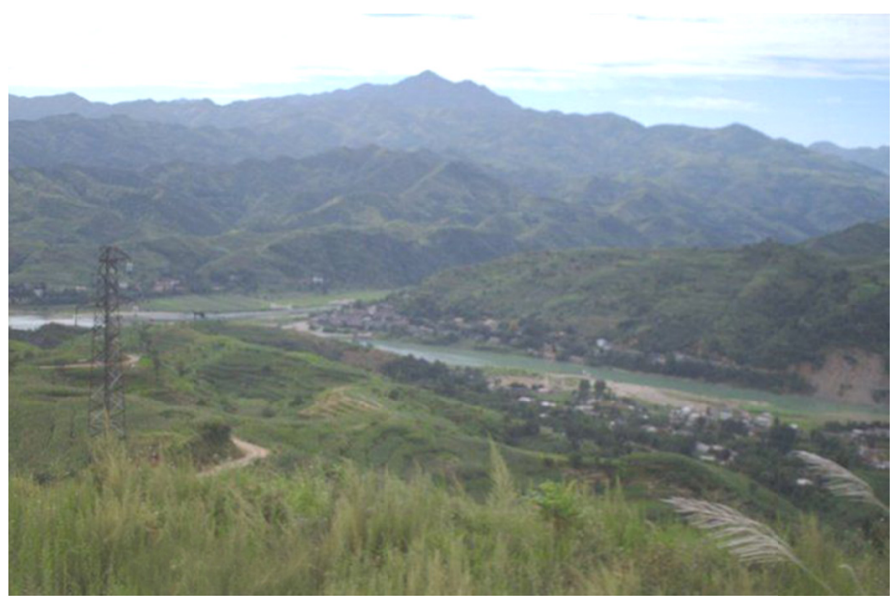

Figure 3. Full view of Yanzibian

\subsection{Residence Determination - The Building Pattern of Adjusting Measures to Local Conditions}

The silted buildings for residence alongside rivers are mostly constructed nearby the mountains. This is the so-called "neutralized wood and air, plentiful water ions, fresh air, green hills and clear water and cultivation of humanity" (Wang Dayou, 2005, p. 50). In Yanzibian, most of silted buildings use the wooden construction of column and tie to form a firm grid system. The most basic feature of silted buildings is that the porter is usually constructed on the ground and one side of the wing-rooms on the left side and the right side is connected with the porter on the found and the other three sides are both suspended in midair. And the three sides are supported by wood stakes. This forms a hanging stilt, which is so-called the ecological characteristics of "flat heaven and uneven earth".

In order to get a perfect ventilation effect, a large majority of silted buildings are constructed in three storeys. 
The first storey is usually used to store goods or rear livestock in pens. The second storey and the third storey are used for daily life and activities. In order to increase space for activities, a hanging corridor is constructed outside the ground of the second floor. On a muggy and humid climate condition, in order to avoid the wood structures of the building from being mortified as a result of humidity, the surroundings of the top floor and the down floor are usually not enclosed by a dead wall. This, to the greatest extent, enables the wind pressure to form a cross ventilation and to ensure the aeration cooling in the room. Therefore, the silted building hangs over the ground not only for aeration drying, but also prevents threats from poisonous snakes and wild animals.

\section{Traditional Building Technique}

\subsection{Original Ecology - The Material Using Mode of Using Local Materials}

The so-called ecological material means that the material grows out of the nature and then returns the nature after it runs out, which forms an ecological system of a great natural and systematic circulation (Liu Su, 2011, p64). The materials for constructing silted building in the local area are mainly such ecological materials as bamboo, wood, stone, white lime, tile and oil plants, etc. The mountains in Yanzibian are continuous with ups and downs and the bamboo and wood resources are abundant. Thin bamboo, pine wood and cedarwood are the main building raw materials, which are all selected in the local area. In the local area, people take advantage of the characteristics of processing, dismantling and repeated usage of wood to build a house. The bamboo is weaved and used to fill in the double wall (See Figure 4). The toughness of bamboo itself enhances the anti-seismic property of the wall. In order to avoid the danger that the stake is soaked in the water for a long time, the local people use shale which is a kind of stone material with high rigidity and bad hydrophilic performance in construction of the base component that faces the water. As a kind of decorative coating, the white lime is smeared on the outside layer of the wall which is simple and concise. Tile is fabricated with fire by local people themselves. It has strong consolidation and resistance to corrosion and is more capable of enduring washing of rainwater and sand wind compared with cob root and it is often used together with soil. Oil plant refers to tung oil. Tung oil is a kind of excellent and dry plant oil and is used on the outside of wood materials, which is simple and unadorned and has the protection effects of anti-septic, moisture proof and mothproof.
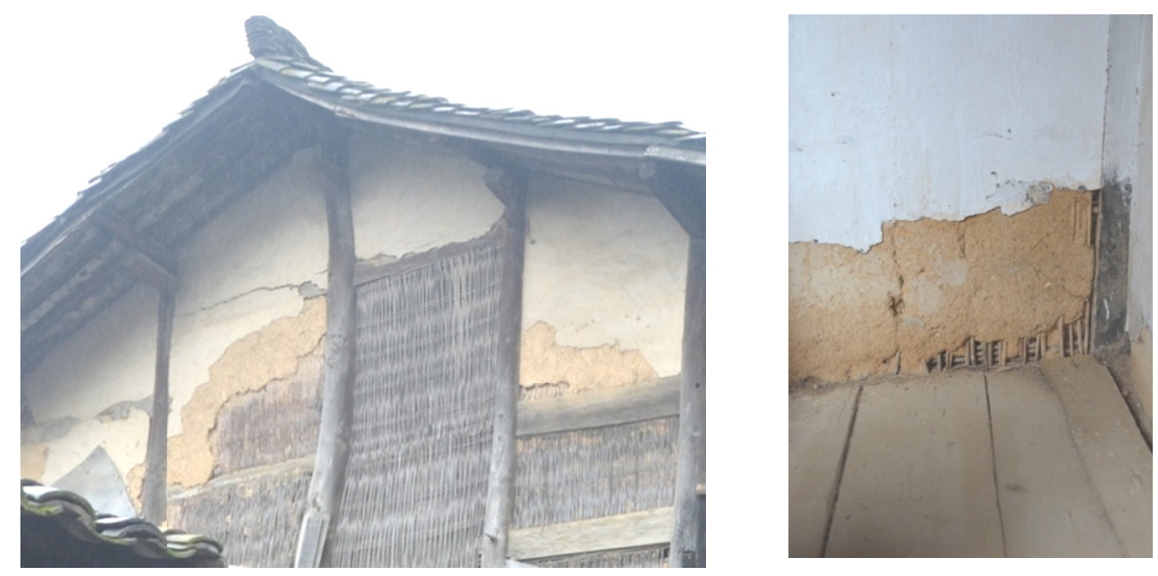

Figure 4. Double wall

\subsection{Hard Structure - The Building Technique of Ecological Concept}

\subsubsection{The Structure of the Wall}

Influenced by local climate, the wall next to the street is mostly enclosed by the pattern of the traditional plank door. The wall within the courtyard and the overhanging wall are mostly double walls. Within the wall is fixed with weaved bamboo and outside the wall is covered and floated with cob. Although the wall in itself does not have the effect of load-bearing, the encapsulated wood structure within the wall is the load-bearing structure of the building.

According to the above type of building, we can then interpret the four major ecological merits of the wall of silted building. The first merit is its fire protection. The clay used in the soil wall is a kind of fire-proof material. Addition of admixture (macadam, sand and aggregate chips, etc.) has the effect of consolidation on the wall, which, at the same time, has the effect of fire protection. The second merit is moisture proof. The adobe wall 
itself does not have the effect of moisture proof and it becomes softened once it is mixed with water. In the construction of the wall, grait is used as the basic damp-proof course and the wall space is often smeared by cob in a well-distributed way, which has a good antiseptic moisture-proof effect. The third merit is the microclimate adjustment effect. The summer in Yanzibian is hot and the sunshine duration is relatively adequate. Sunshine leads to increased temperature of the outer wall. Thus, weaved thin bamboo is added in the process of building a wall. A lot of air is left in the thin bamboo stalk, which forms an air insulating layer and which makes the wall have good functions of heat preservation and heat insulation. The four and the last merit is the force reduction and anti-shake. Since bamboo reinforcement is added in the wall, this strengthens the toughness of the wall. When an earthquake occurs, the wall is pressed by the bamboo cane and is absorbed in a disperse way. This weakens the effect of the force on the front wall.

\subsubsection{The Structure of the Roof}

The root of silted building in the local area adopts the basic "bone" pattern of sloping root (See Figure 5). The pattern of sloping root has realistic meaning in embodying the ecological features of traditional residential houses in Southern Shaanxi.

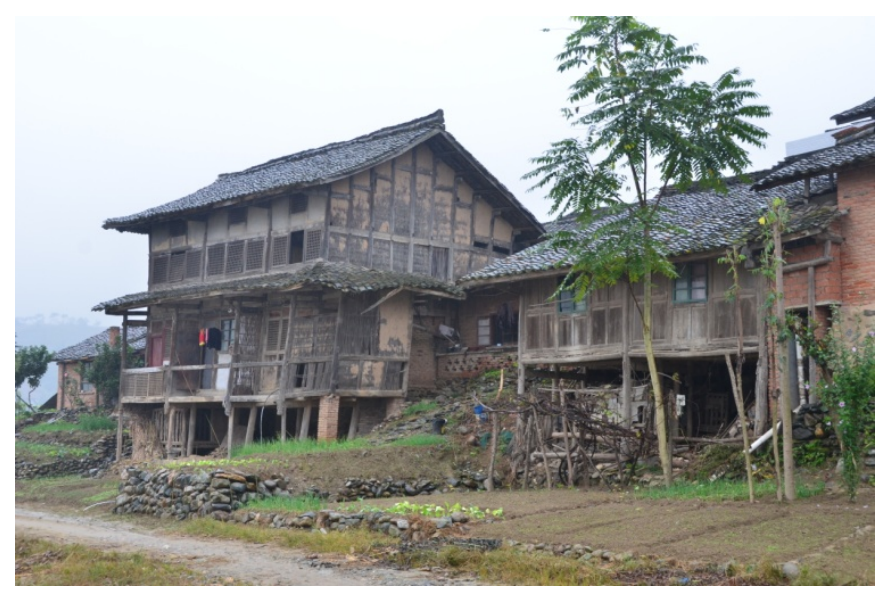

Figure 5. Silted building and sloping root in Yanzibian

On one hand, the sloping roof of Southern Shaanxi is usually constituted by tiling and cant strip. Between the two layers of tile is naturally one layer of air interlayer which has the performance of strengthening thermal insulation and heat insulation. Since the slope of the root is large and is convenient for drainage of water, it has a perfect effect of insulating rainwater. On the other hand, since the temperature difference in the summer in Yanzibian is great, the high root can play a good role of transitional space. The eave overhangs far. This is not only aimed to speed up drainage of water, but also the far-reaching overhanging eave helps to make the room in a low temperature of shadow for a long time and reduce the possibility that the sunshine directly radiates the wall. This also can prevent the rainwater from soaking the base layer of the wall when it drips, which reduces the direct damage of rainwater to the wall.

\subsubsection{The Structure of the Ground}

Construction of the ground of silted building is relatively simple. Its foundation part is usually constructed with rock or grait. The first layer of ground is pieced together by board, having perfect performance of heat preservation, thermal insulation and humidity resistance. On the second layer and the third layer of ground, the lower layer is laid with board, the middle layer is mingled with two layers of tiles which have the effect of consolidation, and the top layer is laid with a layer of board. Some houses are laid with fabricated board. Under the ground is keel and on the keel is supported with board. In order to make it ventilated and moisture proof, each board with have a crack less than $1 \mathrm{~cm}$ in advance. In the rainy season of summer, the board can be torn down to store in order to prevent the board from going mouldy.

\subsection{Soft Space - The Ecological Effect of Transitional Space}

\subsubsection{Parvis - The Effect of Filtering}

The space of parvis is the result that people gradually improve and develop the residential buildings to respond to the local moisture and rainy natural environment. As the old saying goes, "A good and wealth parvis in a 
building is mostly upright, foursquare and neat. And in a good parvis, the parvis usually has the meaning of storage. What the parvis stresses is uprightness and foursquareness flourish the parvis. Such natural Yin and Yang rhythm is not necessary to pursue continuously" (Ruoguan Daoren, 1995, p112).

Its ecological presentation: 1) Lighting and ventilation. As the distance between buildings in the courtyard of a traditional residential house is relatively short, lighting and ventilation in the courtyard is not smooth and the parvis has a good effect of adjustment. 2) Collection and excretion. The so-called "Four water running to the hall" has the meaning of draining off rainwater to the parvis through the eave hanged from the parvis, which also has the meaning that rich water should be kept in one's own field. As for the silted building, an open parvis can bring in clean air from a high altitude. One part of air discharged from the room is drained out to the courtyard through the drainage ditch of the parvis under the effect of gravity. Another part of light air will escape from the parvis. Air inside and outside the room is continuously exchanged, which has the effect of purifying the air. 3) In addition, the parvis is an open space where privacy is relatively weak, which forms a transitional space for the inside and outside environment of the room.

\subsection{2 "Guobai" - The Effect of Moisture Protection}

In the traditional Chinese architecture, "Guobai" is a method to deal with the vision of space. As a matter of fact, it reflects a phenomenon of an architecture group in spatial combination and is application of the aesthetic experience of the ancients. It can be said that, "Guobai" takes advantage of the skillful distance between the door and the scenery and uses the method of mingled scenery and enframed scenery to let a close view and the distant view to fall into the vision of a viewer. The feeling of the view should not be complete, but should be comfortable, so as to satisfy the aesthetic need of the ancients. Here, "Bai" refers to the light of the sky, so that not only the viewer can view the ridge of another building at the opposite, but also a thin of sky is required to remain in the vision to attain "balance of Yin and Yang". This thin of sky, similarly, relates to the lighting and sun adoption in the room and has certain effect of moisture protection and damp protection (See Figure 6). Appropriate control and adjustment of the distance between different buildings can effective prevent the phenomenon of "extensive moisture" on the land in the parvis in the house. It is necessary to adjust or control the height of "Guobai" according to the climate feature, architectural direction and elevation of the residential buildings so as to attain conversion and balance of Yin and Yang and to promote better improvement of the light environment and heat environment in the parvis.
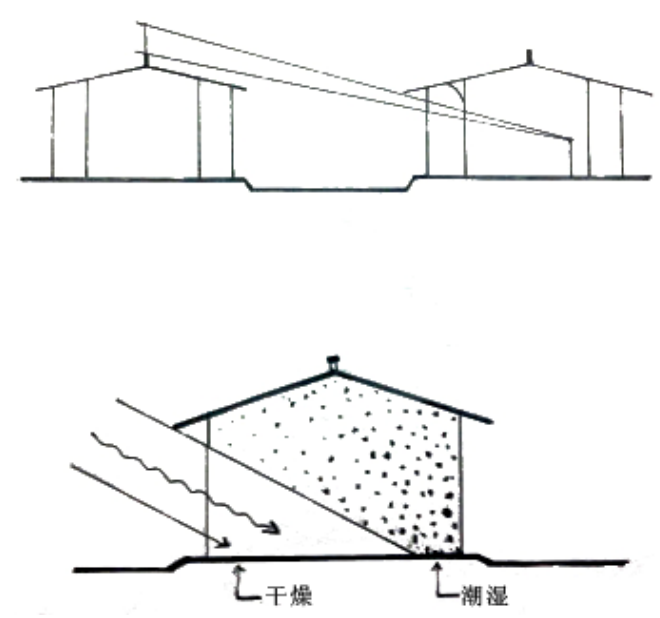

Figure 6. The principle of "Guobai"

\section{Concluding Remarks}

Ecological environment plays a restrictive role in the development of human kind, while development of human kind is a process that continuously adapts to and modifies the environment to satisfy the demand of human kind. This is exactly an interactive mode between man and the nature. Whether in terms of aesthetics, selection of site, selection of materials and design or in terms of building, the silted buildings in Yanzibian in Hanzhong of Southern Shaanxi imply abundant ecological wisdom. The characteristics are delicate, pretty and simple aesthetics, pattern next to the mountains, local use of materials, wonderful art and excelling nature in design and building adjusting measures to local conditions. All these characteristics are the result of long term co-existence 
and co-survival of local people with the ecological environment that they depend on. This promotes silted building to play a harmonious and organic role in the ecological environment system. If these ecological features can be protected, developed and used, it is believed that this will be of great benefit to ecological residential housing and new rural construction in the future. And this will create ecological home that is more appropriate for human kind to reside in.

\section{References}

Jing, Q., \& Zhang, L. (2010). Ecological House (Vol. 3, p. 6). Wuhan: Huazhong University of Science and Technology Press.

Liu, S. (2011). Design Theory and Method of Ancient Architecture (Vol. 9, p. 64). Beijing: China Building Industry Press.

Ruoguan Daoren. (1995). Eight Curtilage Mirror (p. 112). Beijing: Hualing Publishing House.

Wang, D. (2005). Ideal Home of Human Kind (p. 50). Beijing: China Morden Economics Publishing House.

Zhou, M. (2012). Appreciation of a Building - A View on How the Ancient People and the Contemporary People Build a Residential Environment (Vol. 2, p. 2). Chengdu: Southwest Jiaotong University Press.

\section{Copyrights}

Copyright for this article is retained by the author(s), with first publication rights granted to the journal.

This is an open-access article distributed under the terms and conditions of the Creative Commons Attribution license (http://creativecommons.org/licenses/by/3.0/). 